- News \& Views •

\title{
The 2020 Summer Floods and 2020/21 Winter Extreme Cold Surges in China and the 2020 Typhoon Season in the Western North Pacific
}

\author{
Chunzai WANG ${ }^{* 1,2,3}$, Yulong YAO ${ }^{1,2,3}$, Haili WANG ${ }^{1,2,3}$, Xiubao SUN ${ }^{1,2,3}$, and Jiayu ZHENG ${ }^{1,2,3}$ \\ ${ }^{1}$ State Key Laboratory of Tropical Oceanography, South China Sea Institute of Oceanology, \\ Chinese Academy of Sciences, Guangzhou 510301, China \\ ${ }^{2}$ Southern Marine Science and Engineering Guangdong Laboratory (Guangzhou), Guangzhou 511458, China \\ ${ }^{3}$ Innovation Academy of South China Sea Ecology and Environmental Engineering, \\ Chinese Academy of Sciences, Guangzhou 510301, China
}

(Received 1 March 2021; revised 7 April 2021; accepted 9 April 2021)

\begin{abstract}
China experienced significant flooding in the summer of 2020 and multiple extreme cold surges during the winter of 2020/21. Additionally, the 2020 typhoon season had below average activity with especially quiet activity during the first half of the season in the western North Pacific (WNP). Sea surface temperature changes in the Pacific, Indian, and Atlantic Oceans all contributed to the heavy rainfall in China, but the Atlantic and Indian Oceans seem to have played dominant roles. Enhancement and movement of the Siberian High caused a wavier pattern in the jet stream that allowed cold polar air to reach southward, inducing cold surges in China. Large vertical wind shear and low humidity in the WNP were responsible for fewer typhoons in the first half of the typhoon season. Although it is known that global warming can increase the frequency of extreme weather and climate events, its influences on individual events still need to be quantified. Additionally, the extreme cold surge during 16-18 February 2021 in the United States shares similar mechanisms with the winter 2020/21 extreme cold surges in China.
\end{abstract}

Key words: extreme weather and climate events, climate variability, climate change, summer floods, winter cold surge, typhoon activity

Citation: Wang, C., Y. L. Yao, H. L. Wang, X. B. Sun, and J. Y. Zheng, 2021: The 2020 summer floods and 2020/21 winter extreme cold surges in China and the 2020 typhoon season in the western North Pacific. Adv. Atmos. Sci., 38(6), 896-904, https://doi.org/10.1007/s00376-021-1094-y.

\section{Introduction}

The year 2020 was extraordinary and unusual because of the sudden outbreak of the COVID-19 pandemic, which almost paralyzed the world. From the meteorology and oceanography points of view, the year 2020 was also exceptional because extreme weather and climate events occurred over many places of the world. In the summer of 2020, rainfall in many provinces of China was very intense, causing flooding disasters in the Yangtze River Valley (YRV), which were described as the worst since at least 1998. According to the Ministry of Emergency Management of China, as of 13 August 2020, the floods had affected 63.46 million people, led to the death or disappearance of 219 people, and caused a direct economic loss of 178.96 billion CNY. In the winter of 2020/21, cold surges swept most parts of China, prompting the National Meteorological Center to issue its highest cold surge warning alert for the first time in four years. Many weather observing stations across the country met or exceeded their lowest temperature records since such record keeping began. The typhoon season of 2020 in the western North Pacific (WNP) had 23 named storms, which is slightly below the seasonal average of 27 , but the activity during the first half of the typhoon season was far below average for that period. This article discusses the extreme weather and climate events that occurred in China over the last year and describes their possible mechanisms from the perspective of the oceans and climate change.

\footnotetext{
* Corresponding author: Chunzai WANG

Email: cwang@scsio.ac.cn
} 


\section{Summer floods}

During June and July (JJ) 2020, large-scale and continued heavy rainfall led to catastrophic flooding in large areas of central and eastern China. Figure 1a shows the rainfall anomalies over China during JJ 2020 relative to the climatological mean of 1981-2010. As shown, strong positive rainfall anomalies are located in the YRV region. To examine and compare the rainfall variations, we define the rainfall index by calculating the average rainfall anomalies in the YRV region $\left(110^{\circ}-121^{\circ} \mathrm{E}, 28^{\circ}-34^{\circ} \mathrm{N}\right)$. As shown in Fig. 1b, the standardized YRV rainfall for JJ 2020 is very large and greater than 4.0, which breaks the rainfall record since 1979 and is about 3-4 times the JJ rainfalls from 1979 to 2019.

Since it takes time for the atmosphere to respond to oceanic changes, we examine the distribution of sea surface temperature (SST) anomalies in May 2020 over the global oceans (Fig. 1c). The tropical Pacific shows La Niña conditions with cold SST anomalies in the equatorial eastern Pacific, which evolved from a weak central Pacific type of El Niño in the preceding winter of 2019/20. The warm conditions in the Northern Indian Ocean (NIO) in May 2020 are developed from the super Indian Ocean dipole in 2019 (Takaya et al., 2020; Zhou et al., 2021). As is the usual case after an El Niño event in the preceding winter, the tropical North Atlantic also displays warm SST anomalies in the following spring. Following Enfield et al. (1999), the tropical North Atlantic (TNA) is defined as the region of $55^{\circ}-15^{\circ} \mathrm{W}, 5^{\circ}-25^{\circ} \mathrm{N}$. To investigate the roles of these oceanic variations in the YRV rainfall, we calculate regressions of JJ rainfall anomalies onto the NIO SST anomalies $\left(50^{\circ}-100^{\circ} \mathrm{E}, 0^{\circ}-24^{\circ} \mathrm{N}\right)$, the Niño-3 index, and the TNA SST anomalies (Figs. 2a-c). The NIO SST is correlated with the YRV rainfall, whereas ENSO is related to rainfall in southern China. Figure 2c shows that the TNA SST is not significantly correlated with the rainfall in the YRV region; however, this is not the whole story.

In studying the YRV rainfall in June 2020, Zheng and Wang (2021) found that the positive SST anomalies in May over the tropical western North Atlantic (WNA; $80^{\circ}-56^{\circ} \mathrm{W}, 18^{\circ}-28^{\circ} \mathrm{N}$ ) induce positive geopotential height anomalies in June over the midlatitude North Atlantic, which affect the rainfall anomalies in the YRV via an Atlantic-induced atmospheric "wave train" across Eurasia. Here, we also calculate the regression of JJ rainfall anomalies onto the May WNA SST anomalies (Fig. 2d). The May WNA SST anomalies are significantly correlated with the JJ YRV rainfall. This suggests that in addi-

(a) Rainfall anomalies in JJ 2020

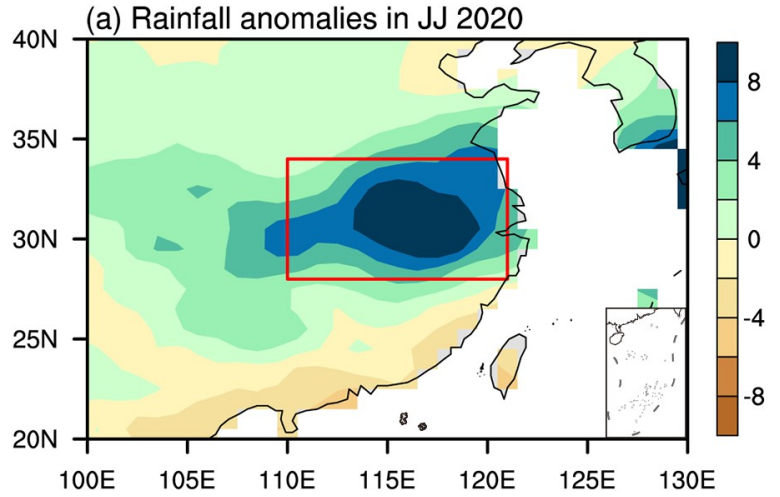

(b) JJ Yangtze River Valley rainfall index

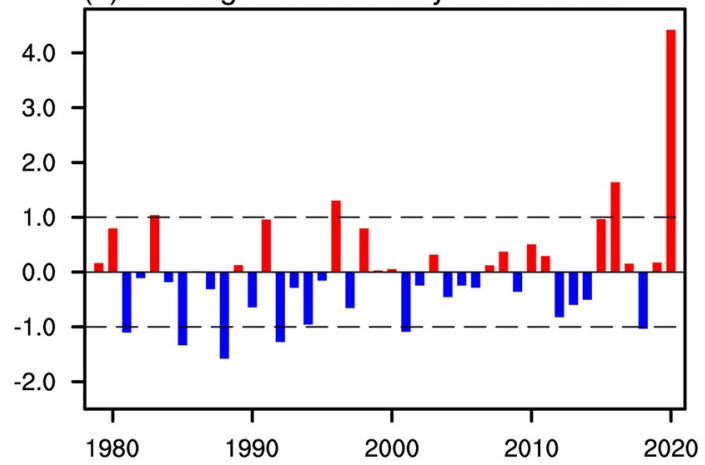

(c) SST anomalies in May 2020

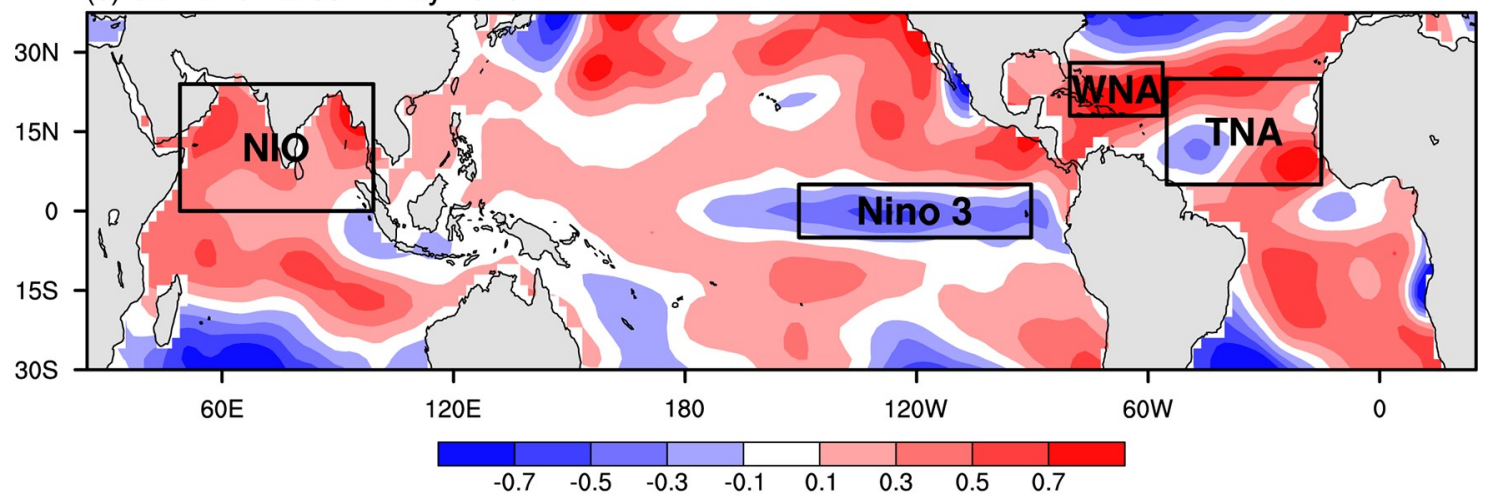

Fig. 1. Rainfall and SST anomalies in June-July (JJ) 2020. (a) Rainfall anomalies ( $\mathrm{mm} \mathrm{d}^{-1}$ ) over China in JJ 2020. (b) Standardized time series of the JJ rainfall index in the YRV region. (c) SST anomalies $\left({ }^{\circ} \mathrm{C}\right.$ ) in May 2020. The red box in (a) represents the YRV region $\left(110^{\circ}-122^{\circ} \mathrm{E}, 30^{\circ}-34^{\circ} \mathrm{N}\right)$. NIO, TNA, and WNA stand for the Northern Indian Ocean $\left(50^{\circ}-100^{\circ} \mathrm{E}, 0^{\circ}-24^{\circ} \mathrm{N}\right)$, Tropical North Atlantic $\left(55^{\circ}-15^{\circ} \mathrm{W}, 5^{\circ} \mathrm{N}-25^{\circ} \mathrm{N}\right)$, and Western North Atlantic $\left(80^{\circ}-56^{\circ} \mathrm{W}, 18^{\circ}-28^{\circ} \mathrm{N}\right)$, respectively. The Niño-3 box is in the equatorial eastern Pacific $\left(150^{\circ}-90^{\circ} \mathrm{W}, 5^{\circ} \mathrm{S}-5^{\circ} \mathrm{N}\right)$. The rainfall data are from NOAA's Precipitation Reconstruction over Land dataset and SSTs are NOAA's ERSST version 5 . 
(a) Reg(June rainfall, May NIO SST)

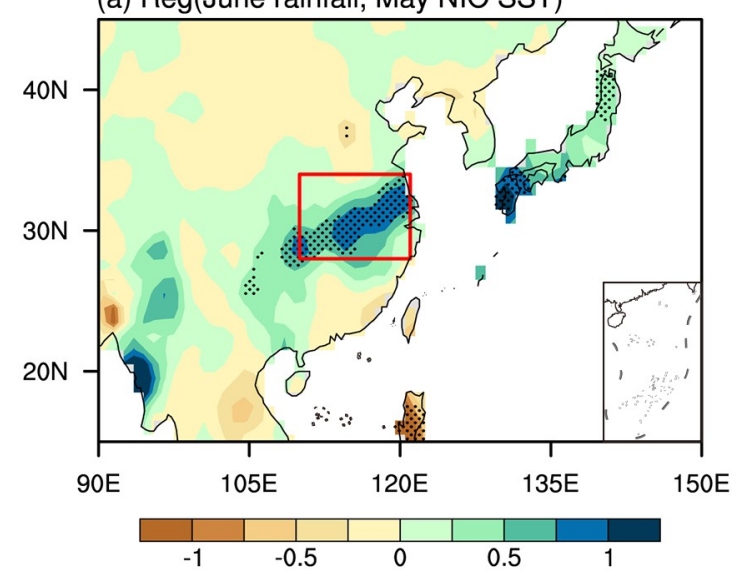

(c) Reg(June rainfall, May TNA SST)

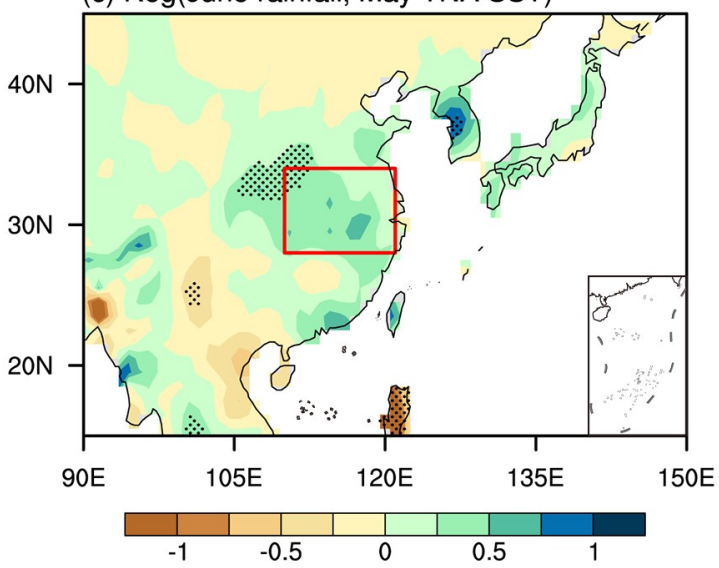

(b) Reg(June rainfall, May Nino 3)

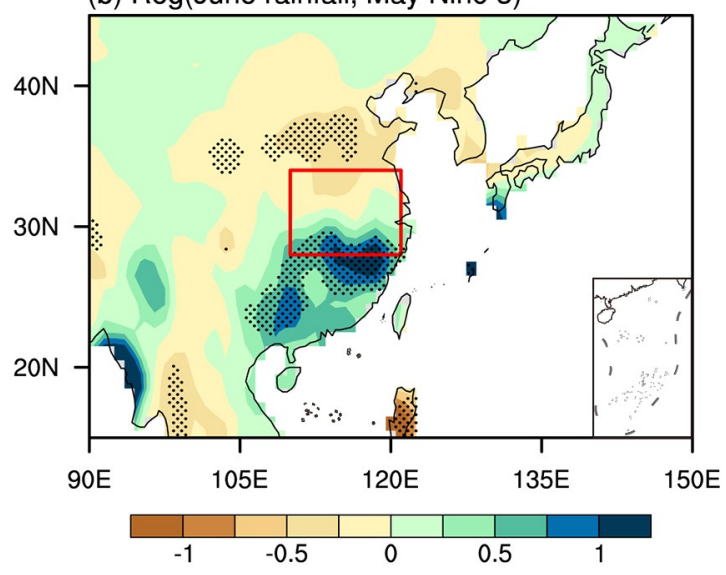

(d) Reg(June rainfall, May WNA SST)

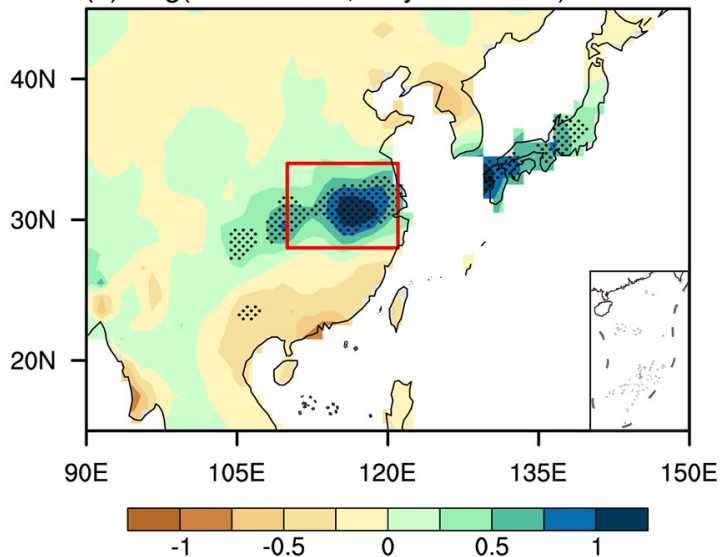

Fig. 2. Relationships of June-July (JJ) rainfall anomalies with SST anomalies. (a) Regression of JJ rainfall anomalies onto NIO May SST anomalies. (b) Regression of JJ rainfall anomalies onto the May Niño-3 index, (c) Regression of JJ rainfall anomalies onto the TNA May SST anomalies, (d) Regression of JJ rainfall anomalies onto WNA May SST anomalies. The areas of rainfall anomalies significant at the $95 \%$ confidence level are dotted.

tion to conditions in the NIO, conditions in the WNA are also important for JJ heavy rainfall in the YRV of China.

To fully understand each ocean's influences on the summer rainfall in the YRV, separate analyses of June and July rainfall anomalies are necessary. As shown in Zheng and Wang (2021), the significant regression of June rainfall anomalies onto the NIO May SST anomalies is mainly outside of the YRV region. The modeling results of Takaya et al. (2020) also show that the rainfall influence of the Indian Ocean SST anomalies is outside of the YRV region. It seems that the June rainfall anomalies in the YRV cannot be explained by the NIO May SST anomalies. However, both the June and JJ rainfall anomalies in the YRV are significantly related to the May SST in the WNA. In summary, the Indian Ocean does not relate to the June rainfall over the YRV, but the WNA does. If we consider the June and July rainfall together, both the Indian Ocean and WNA are important.

Another consideration is the relationship of the 2020 summer floods in China with global warming. Almost all climate models indicate that "wet gets wetter, dry gets drier" based on studies and assessments of historical and future climate change, but the models often do not agree over land (Held and Soden, 2006). We use rainfall observations to calculate the rainfall trend over China. Our calculation shows an increased rainfall trend during the past 70 years in most areas of China (figure not shown), which is consistent with the results presented in the Blue Book on Climate Change in China (CMA Climate Change Centre, 2020). Although it is hard to attribute an individual extreme rainfall event to global warming, many efforts of "event attribution" have been made (e.g., Trenberth et al., 2015; Diffenbaugh et al., 2017).

\section{Typhoon activity}

Tropical cyclones (TCs) or typhoons can form any time of year in the WNP. The 2020 typhoon season in the WNP is unique compared to previous seasons. Figure 3a shows that the number of TCs in the first seven months of 2020 is lower than the climatological mean, whereas the number of TCs during the second half of the year (August to December) is gener- 
(a) TC frequency

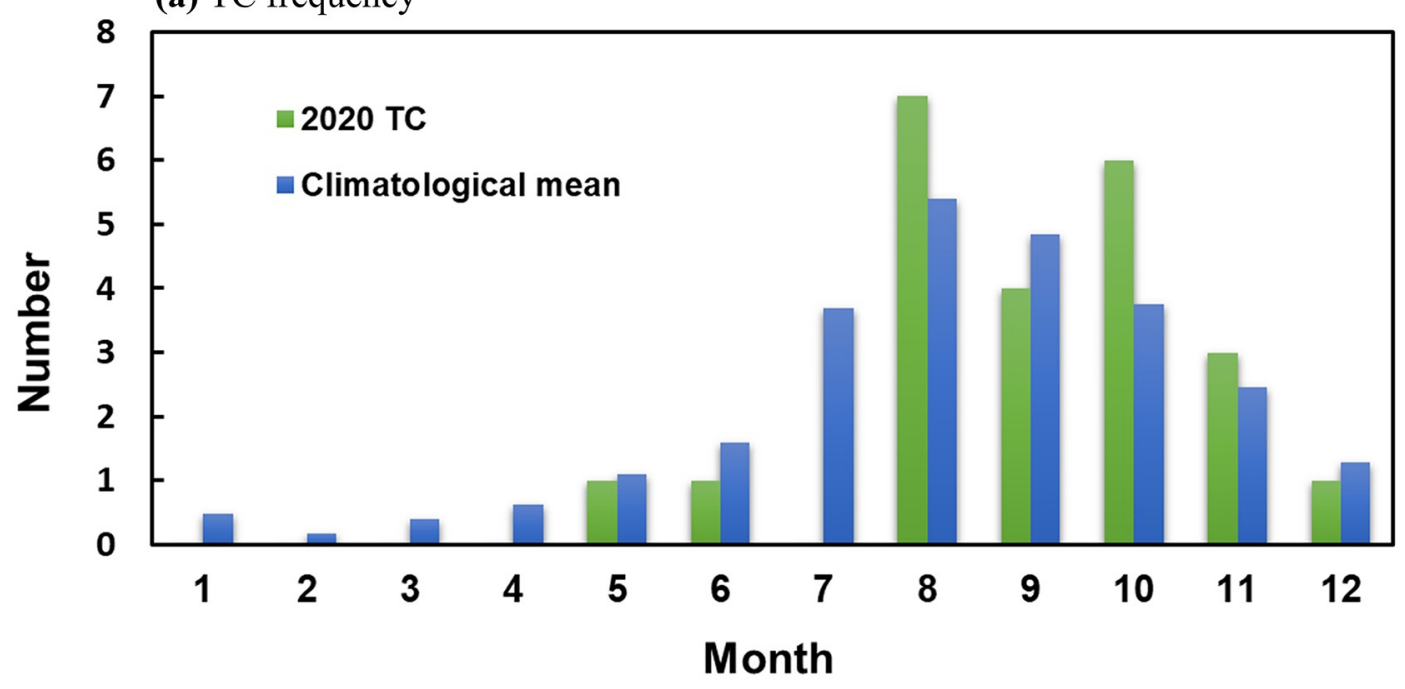

(b) Wind shear anomalies

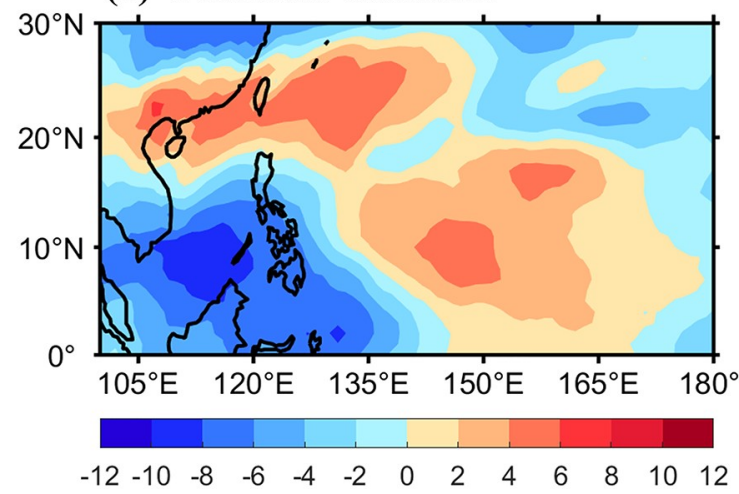

(c) Humidity anomalies

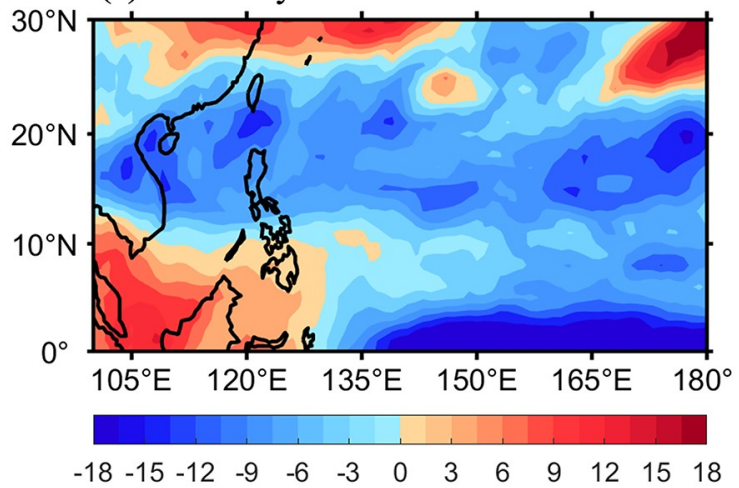

Fig. 3. Typhoon activity and large-scale environmental factors in 2020. (a) The number of tropical cyclones (TCs) in 2020 and climatological mean TCs. (b) The distribution of vertical wind shear anomalies ( $\left.\mathrm{m} \mathrm{s}^{-1}\right)$ in June 2020. (c) The $600-\mathrm{hPa}$ relative humidity anomalies $(\%)$ in June 2020 . The vertical wind shear is calculated as the magnitude of the vector difference between winds at $200 \mathrm{hPa}$ and $850 \mathrm{hPa}$. The TC data are from the JTWC (Joint Typhoon Warning Center) and other data are from the ERA5 dataset.

ally higher than the climatological mean. The 2020 typhoon season is unusual because TCs did not form until May 2020 and there were no TCs in July 2020. Overall, the 2020 typhoon season had 23 named storms, which was slightly below the average of 27 but much lower than the average in the first half of the typhoon season. As an example, we plot the distribution of vertical wind shear and 600-hPa humidity anomalies in June 2020 (Figs. $3 \mathrm{~b}$ and c). The WNP shows large positive vertical wind shear and negative humidity anomalies, both of which are not favorable for the formation and development of TCs. Similar conditions exist during other months of the first half of the typhoon season. In contrast, the vertical wind shear is small and humidity is high in the second half of the season, which facilitate the formation and development of TCs.

A natural question is: What is the relationship between global warming and TCs? Observational and numerical modeling studies have reached a consensus regarding the influences of global warming on global TC activity. First, global warming will reduce the number of global TCs because global warming increases the stability of the atmosphere, which is not conducive to the development of atmospheric convection. Second, global warming will increase the intensity of TCs and rainfall since global warming strengthens thermodynamical factors that favor rainfall and intensification of TCs. Third, global warming makes TCs move northward or northeastward, which is not favorable for TCs to landfall in the southeast coast. This is because the warming of the oceans will weaken the subtropical high, thereby changing the TCs' steering flow and driving TCs northward or northeastward. In spite of these consensus results, it is hard to attribute 2020 typhoon activity in the WNP to global warming.

\section{Winter cold surges}

On average, the winter of 2020/21 was not cold in China. The air temperature anomalies at 2 meters from 1 December 
2020 to 20 February 2021 were generally warm except in Northeast and Northwest China (Fig. 4a), consistent with the background of global warming. However, an average warm winter does not mean that extreme cold surges cannot occur. In fact, under the warm winter background, three cold surge events occurred in China: 13-15 December 2020; 29 December 2020 to 1 January 2021; and 6-8 January 2021 (Zheng et al., 2021). Figure 4b shows the air temperature anomalies for the coldest surge event during 6-8 January 2021. The overall temperature anomalies in China were negative except for the QinghaiTibet Plateau, especially in the north and northeast of China where the temperature anomalies were larger than $-9^{\circ} \mathrm{C}$. According to the China Meteorological Administration, this cold surge led to record-breaking low temperatures in many provinces of China such as Inner Mongolia, Hebei, Liaoning, and Shandong.

Sunlight distribution causes the tropics to be warm and the Arctic to be cold, with strong north-south temperature gradients. Associated with the temperature gradients are the strong westerly winds in the middle-high latitudes which are called
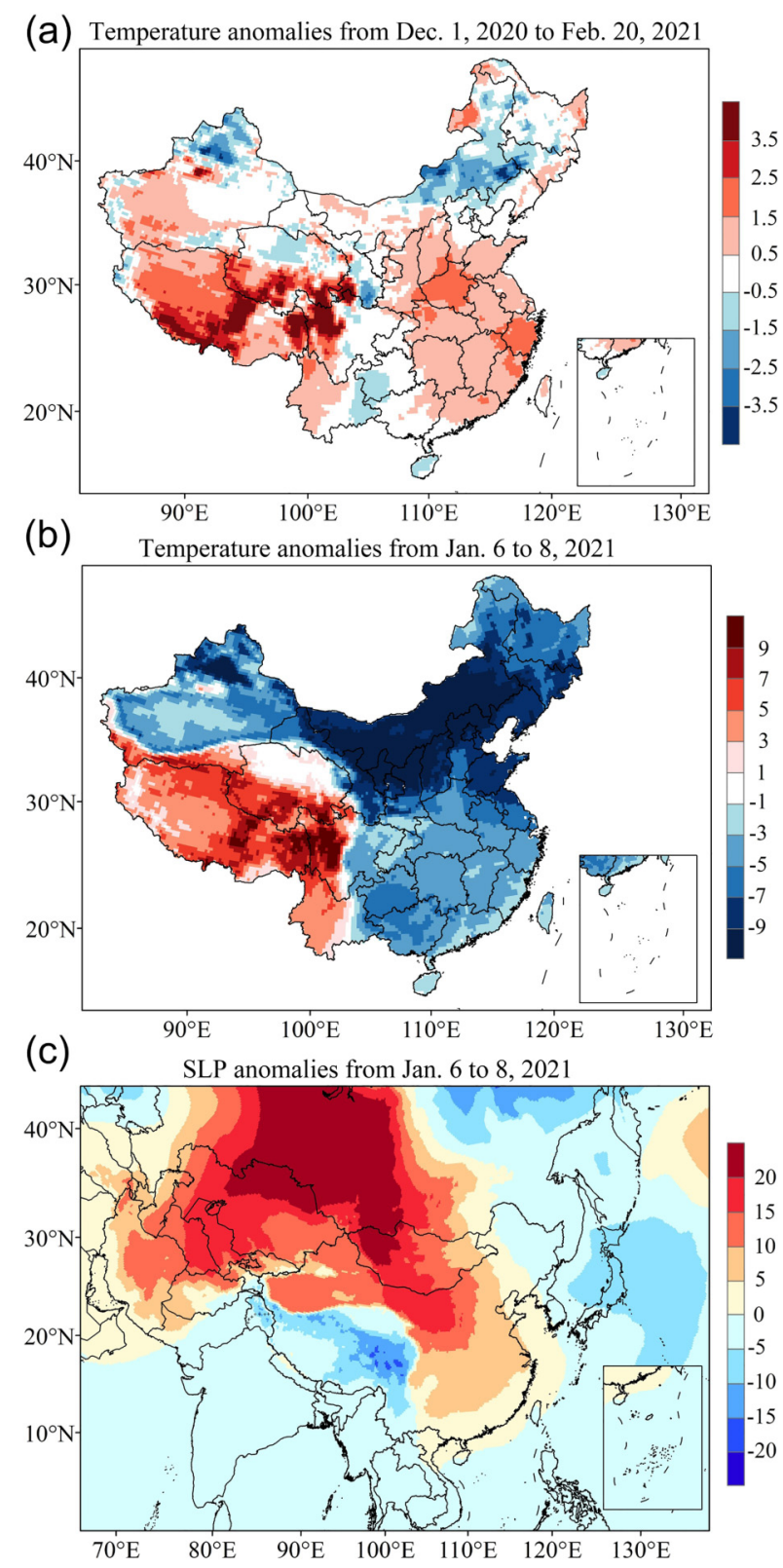

Fig. 4. The distributions of air temperatures at 2 meters and sea level pressure in China. (a) Average temperature anomalies $\left({ }^{\circ} \mathrm{C}\right)$ during the winter of 1 December 2020 to 20 February 2021. (b) Temperature anomalies $\left({ }^{\circ} \mathrm{C}\right)$ during the cold surge of 6-8 January 2021. (c) SLP anomalies (hPa) during the cold surge of 6-8 January 2021 . The data are from the ERA5 reanalysis product. 
the jet stream. In a normal winter, the jet stream is relatively flat, which acts as a lasso of sorts and keeps the cold polar air trapped inside the Arctic (Fig. 5a). A change of the atmosphere can make the flat jet stream become a wavy jet stream (Fig. 5b). Figure 4c shows the distribution of sea level pressure (SLP) anomalies for the cold surge event during 6-8 January 2021. Large positive SLP anomalies are located in the western region of Russia, causing the Siberian High to intensify and move northward. The intensification and northward movement of the Siberian High perturbs the jet stream to be wavy and redirects it in the northwest-southeast direction, allowing the cold polar air to plunge south and resulting in the cold surge event.

Regarding global warming, the wavy jet stream theory still works (e.g., Francis et al., 2015; Ding et al., 2008). The increase of air temperature under global warming is not uniform over the world. The fastest warming rate is occurring in the Arctic, and this phenomenon is called Arctic Amplification (Cohen et al., 2014) in association with the Arctic sea ice decrease. The fast Arctic warming reduces the north-south temperature contrast which affects the strength of the jet stream. The reduced temperature contrast results in a weaker and wavier jet stream, which is more likely to spill the cold polar air southward. Thus, global warming increases the occurrence of extreme cold surge events.

There are other views or hypotheses on the relationship between cold surge events and Arctic sea ice loss. Different from the wavy jet stream theory, Kug et al. (2015) and Mori et al. (2019) suggest that the influences of sea ice loss on cold winters can be operated through a teleconnection pattern. Other studies have proposed that Arctic sea ice loss weakens the stratospheric polar vortex, which induces a negative phase of the Arctic Oscillation at the surface, resulting in low temperat-
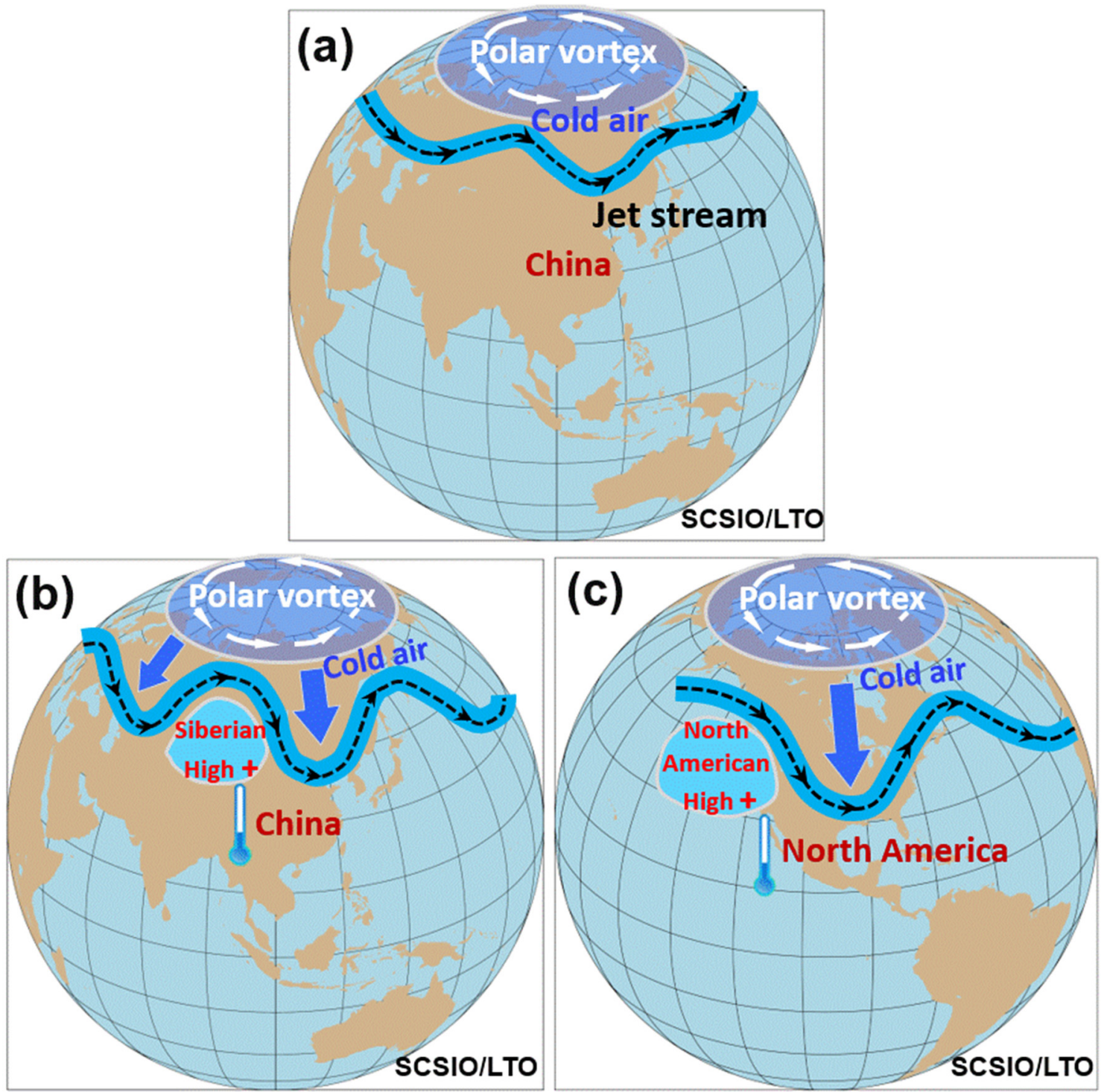

Fig. 5. Schematic diagrams of atmospheric circulation patterns associated with winter cold surges. (a) A normal mild winter with the relatively flat jet stream. (b) A cold surge in China with the enhanced Siberian High and wavy jet stream. (c) A cold surge in the United States with the enhanced North American High and wavy jet stream. The wavy jet stream allows cold polar air to plunge south, thus resulting in a cold surge event. 
ures in midlatitudes (e.g., Kim et al., 2014; Nakamura et al., 2015; Peings and Magnusdottir, 2014). Many other studies found no influences of Arctic sea ice loss on the midlatitudes of Eurasia (Li et al., 2015; McCusker et al., 2016; Ogawa et al., 2018).

Recently, an extreme cold surge event plunged south across the central United States and was one of the coldest events on record for many states in the United States (Fig. 6a). During the cold surge of 16-18 February 2021, temperature anomalies over the entire United States were negative except for parts of the Florida Peninsula and California. The lowest values were centered over Texas reaching a minimum of $-18^{\circ} \mathrm{C}$. As shown in Figs. $5 \mathrm{c}$ and 6 , the mechanisms of the cold surge in the United States are similar to the cold surge event that occurred in China. During 16-18 February 2021, large positive SLP anomalies were located to the west of North America, which were probably caused by the northward extension of the subtropical high. Over North America, the North American High (Reed, 1933) is analogous to the Siberian High in Eurasia. Intensification and movement of the North American High facilitate the wavy jet stream and allow cold polar air to invade southward.

\section{Roles of the oceans and summary}

Are the oceans important for extreme weather and climate events that occur in China? If yes, then how? The anomalous anticyclone in the WNP serves as a bridge that links the oceans with climate variability in China. Figure 7 illustrates that the Pacific, Indian, and Atlantic Oceans can all affect the anticyclone in the WNP, which in turn provides moisture transport to its northwest side and then increases summer rainfall in China. The affected anticyclone in the WNP also changes atmospheric circulation and thermodynamical factors in the WNP, which influence typhoon activity within the basin. It is shown that typhoon activity in the WNP is affected by Indian Ocean SST (Du et al., 2011; Ueda et al., 2018) and tropical North Atlantic SST (Gao et al., 2018). Wang (2019) provides an overview of how the three oceans interact with one another and affect the anticyclone in the WNP and global climate.

In section 4, we did not discuss the roles of the oceans in the winter cold surges in China or the United States. However, the oceans do affect winter temperatures over land. In particular, it is well known that ENSO events can influ-

(a) Temperature anomalies from Feb. 16 to 18,2021

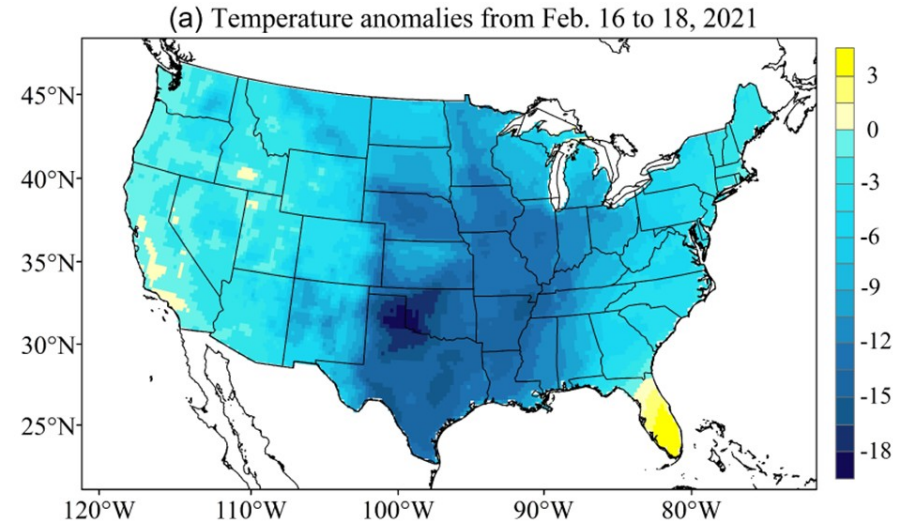

(b) SLP anomalies from Feb. 16 to 18,2021

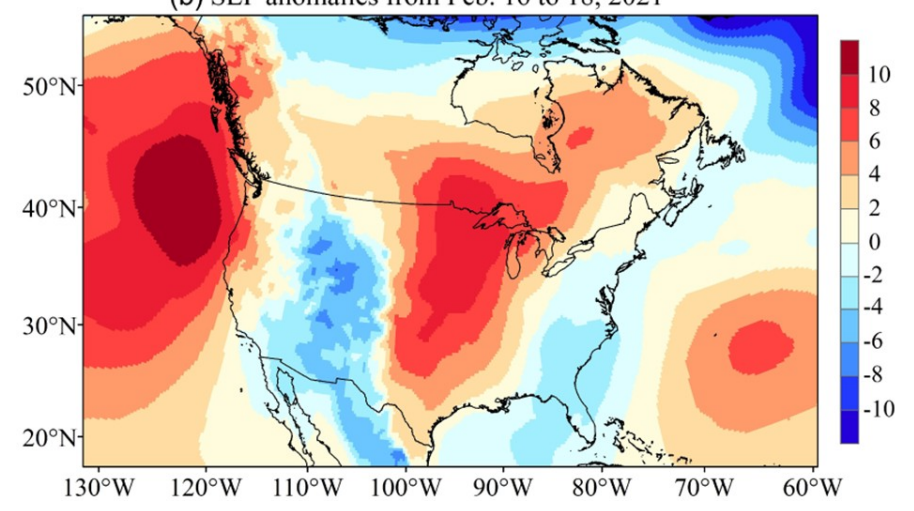

Fig. 6. The distributions of air temperatures at 2 meters and sea level pressure (SLP) in the United States. (a) Temperature anomalies $\left({ }^{\circ} \mathrm{C}\right.$ ) during the cold surge of 16-18 February 2021. (b) SLP anomalies (hPa) during the cold surge of 16-18 February 2021. The data are from the ERA5 reanalysis product. 


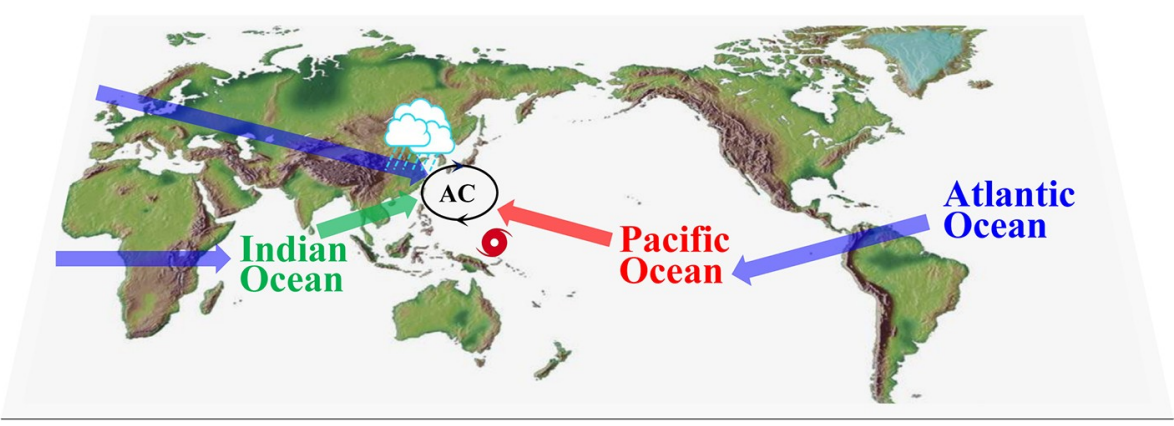

Fig. 7. Schematic diagram showing the influences of three oceans on the western North Pacific (WNP), climate in China, and typhoon activity. AC stands for the anomalous anticyclone in the WNP. All three oceans affect AC in the WNP. The Pacific Ocean's impact on $\mathrm{AC}$ is via processes associated with ENSO events, whereas the Indian Ocean's impact is through Kelvin wave processes. The influences of the Atlantic Ocean on AC have three routes: (1) westward via Rossby wave response; (2) eastward via Kelvin wave response; and (3) eastward across Europe via atmospheric "wave-train".

ence winter temperatures across the globe (e.g., Halpert and Ropelewski, 1992). It is also worthy of mentioning that the tropical Pacific was experiencing a La Niña event during the 2020/21 winter. La Niña events tend to intensify the North American High, which can certainly facilitate cold polar air to intrude southward (Figs. 5 and 6).

In summary, 2020 was an unusual year with summer floods and winter cold surges occurring in China and quiet typhoon activity during the first half of the typhoon season in the WNP. The SSTs in the Pacific, Indian, and Atlantic Oceans all made contributions to heavy rainfall in China, but the Atlantic and Indian Oceans seem to have played dominant roles. The intensification and movement of the Siberian High made the jet stream take on a wavier pattern that allowed the cold polar air to invade southward, and thus induce the cold surges in China. The western North Pacific experienced large vertical wind shear and low humidity during the first half of the typhoon season, both of which are not favorable for the formation and development of typhoons. Global warming can increase the occurrence of extreme weather and climate events; however, the contribution of global warming to an individual extreme weather and climate event is challenging to quantify. The cold surge during 16-18 February 2021 in the United States shares similar mechanisms with the recent cold surges in China.

Acknowledgements. This study is supported by the National Natural Science Foundation of China (Grant No. 41731173), the National Key R\&D Program of China (Grant No. 2019YFA0606701), the Strategic Priority Research Program of the Chinese Academy of Sciences (Grant Nos. XDB42000000 and XDA20060502), the Key Special Project for Introduced Talents Team of Southern Marine Science and Engineering Guangdong Laboratory (Guangzhou) (Grant No. GML2019ZD0306), the Innovation Academy of South China Sea Ecology and Environmental Engineering, the Chinese Academy of Sciences (Grant No. ISEE2018PY06), and the Leading Talents of Guangdong Province Program.

\section{REFERENCES}

CMA Climate Change Centre, 2020: Blue Book on Climate Change in China (2020). Science Press. (in Chinese)

Cohen, J., and Coauthors, 2014: Recent Arctic amplification and extreme mid-latitude weather. Nature Geoscience, 7, 627-637, https://doi.org/10.1038/ngeo2234.

Diffenbaugh, N. S., and Coauthors, 2017: Quantifying the influence of global warming on unprecedented extreme climate events. Proceedings of the National Academy of Sciences of the United States of America, 114(19), 4881-4886, https://doi.org/10. 1073/pnas.1618082114.

Ding, Y. H., Z. Y. Wang, Y. F. Song, and J. Zhang, 2008: Causes of the unprecedented freezing disaster in January 2008 and its possible association with the global warming. Acta Meteorologica Sinica, 66, 808-825, https://doi.org/10.3321/j.issn:05776619.2008.05.014

Du, Y., L. Yang, and S.-P. Xie, 2011: Tropical Indian Ocean influence on Northwest Pacific tropical cyclones in summer following strong El Niño. J. Climate, 24, 315-322, https://doi.org/10.1175/2010JCLI3890.1.

Enfield, D. B., A. M. Mestas-Nuñez, D. A. Mayer, and L. Cid-Serrano, 1999: How ubiquitous is the dipole relationship in tropical Atlantic sea surface temperatures? J Geophys. Res., 104, 7841-7848, https://doi.org/10.1029/1998JC900109.

Francis, J. A., and S. J Vavrus, 2015: Evidence for a wavier jet stream in response to rapid Arctic warming. Environmental Research Letters, 10(1), 014005, https://doi.org/10.1088/1748-9326/10/1/014005.

Gao, S., Z. F. Chen, and W. Zhang, 2018: Impacts of tropical North Atlantic SST on western North Pacific landfalling tropical cyclones. J. Climate, 31, 853-862, https://doi.org/10.1175/JCLI-D-17-0325.1. 
Halpert, M. S., and C. F. Ropelewski, 1992: Surface temperature patterns associated with the southern Oscillation. J. Climate, 5, 577-593, https://doi.org/10.1175/1520-0442(1992)005<0577:STPAWT>2.0.CO;2.

Held, I. M., and B. J. Soden, 2006: Robust responses of the hydrological cycle to global warming. J. Climate, 19, 5686-5699, https://doi.org/10.1175/JCLI3990.1.

Kim, B.-M., S.-W. Son, S.-K. Min, J.-H. Jeong, S.-J. Kim, X. D. Zhang, T. Shim, and J.-H. Yoon, 2014: Weakening of the stratospheric polar vortex by Arctic sea-ice loss. Nature Communications, 5, 4646, https://doi.org/10.1038/ncomms5646.

Kug, J.-S., J.-H. Jeong, Y.-S. Jang, B.-M. Kim, C. K. Folland. S.-K. Min, and S.-W. Son, 2015: Two distinct influences of Arctic warming on cold winters over North America and East Asia. Nature Geoscience, 8, 759-762, https://doi.org/10.1038/ngeo2517.

Li, C., B. Stevens, and J. Marotzke, 2015: Eurasian winter cooling in the warming hiatus of 1998-2012. Geophys. Res. Lett., 42, 8131-8139, https://doi.org/10.1002/2015GL065327.

McCusker, K. E., J. C. Fyfe, and M. Sigmond, 2016: Twenty-five winters of unexpected Eurasian cooling unlikely due to Arctic sea-ice loss. Nature Geoscience, 9, 838-842, https://doi.org/10.1038/ngeo2820.

Mori, M., Y. Kosaka, M. Watanabe, H. Nakamura, and M. Kimoto, 2019: A reconciled estimate of the influence of Arctic sea-ice loss on recent Eurasian cooling. Nature Climate Change, 9, 123-129, https://doi.org/10.1038/s41558-018-0379-3.

Nakamura, T., K. Yamazaki, K. Iwamoto, M. Honda, Y. Miyoshi, Y. Ogawa, and J. Ukita, 2015: A negative phase shift of the winter AO/NAO due to the recent Arctic sea-ice reduction in late autumn. J. Geophys. Res., 120, 3209-3227, https://doi.org/10. 1002/2014JD022848.

Ogawa, F., and Coauthors, 2018: Evaluating impacts of recent Arctic sea ice loss on the northern hemisphere winter climate change. Geophys. Res. Lett., 45, 3255-3263, https://doi.org/10.1002/2017GL076502.

Peings, Y., and G. Magnusdottir, 2014: Response of the wintertime northern Hemisphere Atmospheric circulation to current and projected arctic Sea Ice decline: A numerical study with CAM5. J. Climate, 27, 244-264, https://doi.org/10.1175/JCLI-D-13-00272.1.

Reed, T. R., 1933: The North American high-level anticyclone. Mon. Wea. Rev., 61(11), 321-325, https://doi.org/10.1175/15200493(1933)61<321:TNAHA>2.0.CO;2.

Takaya, Y., I. Ishikawa, C. Kobayashi, H. Endo, H., and T. Ose, 2020: Enhanced Meiyu-Baiu rainfall in early summer 2020: Aftermath of the 2019 super IOD event. Geophys. Res. Lett., 47, e2020GL090671, https://doi.org/10.1029/2020GL090671.

Trenberth, K. E., J. T. Fasullo, and T. G. Shepherd, 2015: Attribution of climate extreme events. Nature Climate Chang, 5, 725-730, https://doi.org/10.1038/nclimate2657.

Ueda, H., K. Miwa, and Y. Kamae, 2018: Seasonal modulation of tropical cyclone occurrence associated with coherent Indo-Pacific variability during decaying phase of El Niño. J. Meteor. Soc. Japan, 96, 381-390, https://doi.org/10.2151/jmsj.2018-044.

Wang, C. Z., 2019: Three-ocean interactions and climate variability: A review and perspective. Climate Dyn., 53, 5119-5136, https://doi.org/10.1007/s00382-019-04930-x.

Zheng, F., and Coauthors, 2021: The 2020/21 extremely cold winter in China influenced by the synergistic effect of La Niña and Warm Arctic. Adv. Atmos. Sci., https://doi.org/10.1007/s00376-021-1033-y.

Zheng, J. Y., and C. Z. Wang, 2021: Influences of three oceans on record-breaking rainfall over the Yangtze River Valley in June 2020. Science China Earth Sciences, https://doi.org/10.1007/s11430-020-9758-9.

Zhou, Z.-Q., S.-P. Xie, and R. H. Zhang, 2021: Historic Yangtze flooding of 2020 tied to extreme Indian Ocean conditions. Proceedings of the National Academy of Sciences of the United States of America, 118, e2022255118, https://doi.org/10.1073/pnas. 2022255118 